\title{
Analytical study of urinary tract infection in adolescent girls
}

\author{
Shubha Srivastava* \\ Department of Obstetrics and Gynecology, Gandhi Medical College, Bhopal, Madhya Pradesh, India
}

Received: 03 March 2018

Accepted: 07 March 2018

\section{*Correspondence:}

Dr. Shubha Srivastava,

E-mail: drshubhasrivastava76@gmail.com

Copyright: $\odot$ the author(s), publisher and licensee Medip Academy. This is an open-access article distributed under the terms of the Creative Commons Attribution Non-Commercial License, which permits unrestricted non-commercial use, distribution, and reproduction in any medium, provided the original work is properly cited.

\begin{abstract}
Background: Urinary tract infection is very common among females in all age groups. During adolescence, hormonal changes favour vaginal colonization by nephritogenic strains of bacteria, which can migrate to the periurethral area and cause urinary tract infection. It is associated with poor self esteem, impaired quality of life, social isolation, and depression. Many factors like low water intake, infrequent voiding and poor menstrual and sexual hygiene have been implicated in UTI during adolescence.

Methods: Girls between 10 and 19 years of age who attended the gynaecology OPD with any urinary complaint such as burning, frequency, pain, blood in urine etc. were included in the study. A questionnaire to obtain demographic profile, symptoms and treatment history was used. Investigations included urine routine examination and culture. Ultrasound was reserved for cases of recurrent UTI.

Results: A total of 25 adolescent girls participated in the study. The most common symptom was burning during micturition which was present in $60 \%$ girls. This was followed by frequency and pain during urination. Recurrent UTI was present in sexually active adolescents. Inadequate water intake, holding urine for long duration and poor menstrual and sexual hygiene were the important etiological factors.

Conclusions: Urinary tract infection is a common problem of adolescence causing much discomfort and loss of school. Inadequate hydration, lack of clean toilets and poor menstrual and sexual hygiene predisposes a young girl to UTI. The need is to educate our girls regarding good hydration and hygiene. Schools and all public places should have basic and clean sanitation facilities.
\end{abstract}

Keywords: Adolescent girls, Menstrual hygiene, Urinary tract infection

\section{INTRODUCTION}

Hall's (1904) influential work at the turn of last century identified adolescence as a distinct developmental stage ${ }^{1}$. The World Health Organization has defined adolescence as the age group 10-19 years.

Agreeably it is a transitional period from dependant childhood to independent adulthood. Therefore, a good physical and mental health of children and adolescents make for good health in adulthood. ${ }^{2}$ Urinary tract infection (UTI) is characterized by bacterial invasion and multiplication involving the kidneys and urinary tract pathways. Approximately $60 \%$ of women will have at least one episode of UTI during their lives. ${ }^{3,4}$

The prevalence of UTI is higher during adolescence, a period in which hormonal changes favour vaginal colonization by nephritogenic strains of bacteria, which can migrate to the periurethral area and cause urinary tract infection. ${ }^{5}$ It is associated with poor self-esteem, impaired quality of life, social isolation, and depression. ${ }^{6}$ Significantly, this health problem is contributing to the overall morbidity of females in all ages of their life. ${ }^{7,8}$ 
This study was carried out evaluate urinary tract infection among adolescent girls attending the outpatient department.

\section{METHODS}

The study was carried out on adolescent girls attending the gynaecology OPD at a private clinic in Bhopal, Madhya Pradesh from July 2012 to June 2013. A total of 272 adolescent girls attended the OPD for various gynaecological problems. An informed consent was taken by the participants and nature of study was explained to them. 25 adolescent girls who fulfilled the study criteria and were willing to participate were included in the study.

The study included all adolescent girls with any these complaints:

- Burning during micturition

- Increased frequency of micturition

- Pain during micturition

- Blood or pus in urine

- $\quad$ Systemic features

\section{Inclusion criteria}

- Age between 10 and 19 years

- Any of the above complaints

- Willingness to participate in the study

\section{Exclusion criteria}

- Adolescents with urogenital malformation

- H/o or presently suffering from medical or surgical renal illness (eg-renal stones, neprotic syndrome)

- Not willing to participate

The investigations performed were

- Urine routine/microscopy

- Urine culture and sensitivity.

- Blood sugar and ultrasonography was done in cases of recurrent UTI.

A self designed peer validated questionnaire was provided which included questions like the symptoms and their duration, any treatment received, amount of fluid intake, frequency of passing urine (before infection), knowledge about menstrual and sexual hygiene. Apart from these, demographic and menstrual history were take note of. The data obtained were collated and analyzed statistically by simple proportions.

\section{RESULTS}

The study was conducted among adolescent girls attending gynaecology OPD at a pivate clinic in Bhopal, MP from July 2012 to June 2013. A total of 272 adolescent girls attended the OPD during the study period for various problems.

Table 1: Reason for attending OPD.

\begin{tabular}{|lll|}
\hline Complaint & Number & Percentage \\
\hline Menstrual abnormality & 122 & $44.8 \%$ \\
\hline Pregnancy & 64 & $23.5 \%$ \\
\hline Urinary tract infection & 25 & $9.1 \%$ \\
\hline Others & 75 & $27.5 \%$ \\
\hline
\end{tabular}

Many girls presented with more than one complaints. The most common complaint for consultation was menstrual abnormality (44.8\%), followed by pregnancy (19.8\%) and then UTI $(9.1 \%)$. The rest presented with other complaints (Table 1).

Table 2: Age wise distribution.

\begin{tabular}{|lll|}
\hline Age group & Number & Percentage \\
\hline$<14$ years & 8 & $32 \%$ \\
\hline $14-18$ years & 11 & $44 \%$ \\
\hline$>18$ years & 6 & $24 \%$ \\
\hline
\end{tabular}

Of the 25 adolescent girls who fulfilled the study criteria and participated in the study, 8 were less than 14 years of age, 11 were between the age 15 and 18 and rest 6 were more than 18 years of age (Table 2 ).

All the girls had attained menarche. Out of 25, eight (32\%) girls were married. 5 (20\%) were pregnant.

Table 3: Symptoms of UTI.

\begin{tabular}{|lll|}
\hline Symptom & Number & Percentage \\
\hline Burning & 15 & $60 \%$ \\
\hline Frequency & 10 & $40 \%$ \\
\hline Pain & 9 & $36 \%$ \\
\hline Blood in urine & 3 & $12 \%$ \\
\hline Others & 8 & $32 \%$ \\
\hline
\end{tabular}

The most common urinary symptom was burning during micturition with 15 (60\% girls) complaining it. This was followed by frequency, pain and blood in urine. Many girls had more than one symptom (Table 3 ).

Table 4: Etiological factors.

\begin{tabular}{|lll|}
\hline Etiological factor & Number & Percentage \\
\hline Infrequent bladder emptying & 18 & $72 \%$ \\
\hline Inadequate water intake & 10 & $40 \%$ \\
\hline Poor menstrual hygiene & 8 & $32 \%$ \\
\hline Improper perineal washing & 8 & $32 \%$ \\
\hline Vaginal discharge & 7 & $28 \%$ \\
\hline Poor nutririon & 3 & $12 \%$ \\
\hline Pregnancy & 5 & $20 \%$ \\
\hline
\end{tabular}

Low water intake $(<4$ glasses) was present in $10(40 \%)$ girls. Infrequent bladder empting was found in $18(72 \%)$ 
girls. Poor menstrual hygiene was present in $8(32 \%)$ girls. Improper perineal washing and poor nutrition was also found in the girls. Four adolescents complained of recurrent UTI. Incidently they were all married and were not practising proper sexual hygiene. Vaginal discharge was present in 7 girls (Table 4).

The culture reports were positive in only $15(60 \%)$ patients. Most common organism was E. coli followed by Staphylococcal group.

\section{DISCUSSION}

Urinary tract infection is among the leading cause of adolescent girls visiting a doctor. We in this small study have tried to analyze the etiological factors and practices which predispose the young girls to UTI. The incidence of UTI in our study was $9.1 \%$. Ahmed and Avasarala in their study found $12.7 \%$ of girls suffering from UTI. ${ }^{9}$ Vyas et al in a study on nursing students found $20 \%$ of study population having UTI. ${ }^{10}$ In their study, they also found a higher prevalence of UTI in 17-20 years of age.

There is a strong association between the quantity of water intake and occurrence of UTI.In our study $40 \%$ of the adolescent girls drank less than four glasses of water a day. Low amount of intake of water not only concentrates urine but also leads to urinary stasis which favors bacterial growth. Vyas et al in their study found a strong association of low levels of water intake and UTI. ${ }^{10}$ Study by Nyagaard et al showed similar results. ${ }^{11}$ The habit of poor water intake leads to prolonged intervals between urination which in turn leads to higher bacterial growth. When enquired further the reason for this behavior in the girls was non availability of clean toilets in schools. Due to this they tended to have lesser amounts of water which led to holding of urine for long and in turn UTI.

Poor perineal and menstrual hygiene and improper sexual hygiene all contributed to UTI. Sexual intercourse heralded UTI in most of sexually active girls and recurrent infections are seen predominantly in this group. Incidence of UTI is more at the initiation of sexual activity. This is because of introduction of pathogens in the vagina. Perineal washing before and after an act intercourse and urinating immediately after definitely lowers the risk of UTI. ${ }^{12}$

Most of these girls did not know the correct method of perineal washing as it has never been discussed with them. Washing before backwards reduces the contamination of genitourinary system with enteric pathogens thus lowering the risk of UTI.

The old age concept of not having a bath during menses and use of non disposable pads is still persisting. Poor menstrual hygiene has been found to be an etiological factor in many studies. Not just these young girls but their mothers also need to be made aware of the importance of menstrual and sexual hygiene. ${ }^{13}$ Menstrual and sexual hygiene should be made a part of the study curriculum for adolescent girls.

During pregnancy the need to take good amount of water and frequent urination has to be emphasized. Approximately, $90 \%$ of pregnant women develop urethral dilation, increased bladder volume and decreased bladder tone, along with decreased urethral tone. These contribute to increased urinary stasis and ureterovesical reflux. ${ }^{14}$ This may lead to UTI and subsequently to many complications. These complications may be related to pyelonephritis, low birth weight, premature labor, preterm birth, hypertension, preeclampsia, and increased incidence of perinatal death. ${ }^{15}$

\section{CONCLUSION}

Urinary tract infection is a common problem of adolescence causing much discomfort and loss of school. Inadequate hydration, lack of clean toilets and poor menstrual and sexual hygiene predisposes a young girl to UTI. The need is to educate our girls regarding good hydration and hygiene. Schools and all public places should have basic and clean sanitation facilities. All pregnant women should undergo urine analysis as UTI in pregnancy may lead to serious complications. Although benign looking recurrent and chronic UTI may damage kidneys and even lead to renal failure in at the end. Hence should be treated promptly and diligently.

\section{Funding: No funding sources \\ Conflict of interest: None declared \\ Ethical approval: Not required}

\section{REFERENCES}

1. Hall GS. Adolescence: its psychology and its relations to physiology, anthropology, sociology, sex, crime, religion and education. New York: D. Appleton and Company;1904: 1844-1924.

2. Ye G. Health promotion of adolescents. Coll Anthropol. 1997;21(1):93-100.

3. Nicolle LE. Uncomplicated urinary tract infection in adults including uncomplicated pyelonephritis. Urol Clin North Am. 2008;35:1-12.

4. Salvatore S, Salvatore S, Cattoni E, Siesto G, Serati $\mathrm{M}$, Sorice P, et al. Urinary tract infections in women. Eur J Obstet Gynecol Reprod Biol. 2011;156:131-6

5. Winberg J, Anderson HJ, Bergstrom T, Jacobsson B, Larson H, Lincoln K. Epidemiology of symptomatic urinary tract infection in childhood. Acta Paediatr Scand Suppl. 1974;252:1-20.

6. Fonda D. Promoting continence as a health issue. Eur Urol. 1997;32:28-32.

7. Ram S, Gupta R, Gaheer M. Emerging antibiotic resistance among the uropathogens. Indian $\mathrm{J}$ Med Sci. 2000 Sep;54(9):388-94.

8. Singh MM, Devi R, Garg S, Mehra M. Effectiveness of syndromic approach in management of 
reproductive tract infections in women. Indian J Med Sci. 2001 Apr;55(4):209-14.

9. Ahmed SM, Avasarala AK. Urinary tract infections (uti) among adolescent girls in rural Karimnagar district, AP - K.A.P. study. Indian J Prev Soc Med. 2009;40:6-9.

10. Vyas S, Varshney D, Sharma P, Juyal R, Nautiyal V, Shrotriya VP. An overview of the predictors of symptomatic urinary tract infection among nursing students. Ann Med Health Sci Res. 2015;5(1):54-8.

11. Nygaard I, Linder M. Thirst at work - An occupational hazard? Int Urogynecol J Pelvic Floor Dysfunct. 1997;8:340-3.

12. Badran YA, El-Kashef TA, Abdelaziz AS, Ali MM. Impact of genital hygiene and sexual activity on urinary tract infection during pregnancy. Urol Annals. 2015;7(4):478-81.
13. Srivastava S, Chandra M. Study on the knowledge of school girls regarding menstrual and reproductive health and their perceptions about family life education program. Int $\mathbf{J}$ Reprod Contracept Obstet Gynecol. 2017;6:688-93.

14. Delzell JE, Jr, Lefevre ML. Urinary tract infections during pregnancy. Am Fam Physician. 2000;61:71321.

15. Scholes D, Hooton TM, Roberts PL, Gupta K, Stapleton AE, Stamm WE. Risk factors associated with acute pyelonephritis in healthy women. Ann Intern Med. 2005;142:20-7.

Cite this article as: Srivastava S. Analytical study of urinary tract infection in adolescent girls. Int $\mathbf{J}$ Reprod Contracept Obstet Gynecol 2018;7:1385-8. 